\title{
Comparative Study between Posterior Approach with Mesopancreatectomy versus Standard Approach in Pancreatoduodenectomy: A Case Control Study
}

Mohamed Abd Elwahab, Ayman El Nakeeb, Mahmoud Abd Elwahab Ali, Hosam Hamed, Ahmed Shehta, Rami Said, Mohamed El Refai, Ahmed El-Geidi, Talaat Abdallah

Corresponding author:

Ayman El Nakeeb, MD

Professor of general surgery,

hepatobiliary and pancreatic surgery

Gastroenterology Surgical Center

Mansoura University, Egypt

Telephone: 002, 0106752021 0502251543

E-mail: elnakeebayman@yahoo.com
Gastroenterology Surgical Center, Mansoura University, Egypt

\section{ABSTRACT}

Background: Mesopancreas is the most common site for $\mathrm{R} 1$ resection and local recurrence. This study was designed to compare standard pancreatoduodenectomy (PD) versus posterior approach pancreatoduodenectomy PAPD in treating pancreatic head cancer.

Methods: All patients underwent PD for pancreatic head cancers from January 2006 to December 2015 were evaluated. Patients were divided into two groups. Group A patients underwent standard PD and group B underwent PAPD. The primary outcome was postoperative survival.

Results: The study included 210 patients in group $A$ and 77 patients in group B. The mean blood loss was significantly lesser in PAPD group $(P=0.007)$. The number of patients with $R 1$ resection was significantly higher after standard $P D$ group $(P=0.04)$. The median survival was 22 months in the standard groups and 23 months in PAPD $(P=0.001) .1$-, 3and 5 -year actuarial survival were $41 \%, 12 \%$, and $0 \%$ in standard group and $51 \%, 21 \%$, and $8 \%$ in PAPD.

Conclusion: PAPD allowed complete mesopancreatic excision and has the advantages of easier technique, less blood transfusion, increased R0 resection and better survival than standard PD.

Key words: pancreatic cancer, pancreaticoduodenectomy, posterior approach pancreaticoduodenectomy, superior mesenteric artery first approach

\section{INTRODUCTION}

Pancreatic head carcinoma is considered to have the worst prognosis of the periampullary carcinomas. About $95 \%$ of all patients diagnosed with pancreatic cancer will die within one year (1-4). Pancreaticoduodenectomy (PD) offers patients with pancreatic head adenocarcinoma the only hope for long-term survival (3-5). However, the 5 -year survival is still $5 \%$ to $20 \%$. Numerous prognostic factors have been reported to improve survival outcome after PD including lymph node status, free resection margins, tumor size, differentiation, and vascular invasion (6-8). 
The technique of PD had been modified in many well designed trials to prevent postoperative pancreatic leakage (9-11) or to achieve negative resection margins which may reflect on improvement of the survival and decrease the recurrence rate (12-14). Although resection margin status has important prognostic factors in pancreatic cancer, controversies still exist regarding impact of RO/R1 resection margin on survival after PD $(3,8,12-16)$. Konstantinidis IT et al reported that patients undergoing an RO resections have an improved survival compared with R1 resections, but this survival benefit is lost when the tumor is within $1 \mathrm{~mm}$ of the resection margin (16).

Posterior approach for PD (PAPD) is one of many modification of the technique of $P D$, and is one of superior mesenteric artery (SMA) first approaches to PD. PAPD provides early identification of unresectable pancreatic head cancer by early dissection of superior mesenteric artery without dividing pancreatic neck and a replaced right hepatic artery can be detected easily. In addition to previous advantages of PAPD, a complete resection of mesopancreas as well as an adequate lymph node dissection can be achieved $(14,17,18)$.

Mesopancreas, consisting of the fibrofatty tissue between the posterior surface of the pancreatic head to behind the mesenteric vessels, is the most common site for R1 resection and local recurrence. Complete excision of the mesopancreas is thus expected to be associated with better survival compared to standard PD (19-21).

There are several studies describing the operative technique of PAPD, but there is only one paper compared both PAPD and standard PD outcomes but with small sample size $(12-14,18,20)$. We previously published our modification on PD focusing on the technique of the operation and analyzing the preliminary results (26). We therefore compared PAPD and standard PD in patients with pancreatic head carcinoma in this retrospective study. The intraoperative data and postoperative outcome including (long-term survival, resection margin, lymph node dissection, and recurrence rate) were compared in both groups of patients.

\section{MATERIALS AND METHODS}

\section{Study design}

We retrospectively studied patients who underwent PD for pancreatic head adenocarcinoma in our Gastroenterology Surgical Center, Mansoura University, Egypt, from January 2006 to December 2015. Excluded from analysis were all patients with other peri- ampullary tumour, pancreatitis, solid pseudopapillary tumour, neuroendocrinal tumour, patients with liver cirrhosis, and patients who underwent pancreaticojejunostomy as all PAPD patients underwent pancreaticogastrosotmy.

The medical records of patients were reviewed and collected in December 2017. In our center the data are recorded in a prospectively prepared computerized pancreatic surgery sheet since 2000 which had all preoperative, intraoperative and postoperative data for each patient (routine prospective practice). This study was approved by Institutional Review Board. This study included two groups of patients. Group A patients (control group) who underwent standard PD and group $B$ who underwent PAPD. The selection of the approach was based on surgeon preferences.

\section{Preoperative assessment}

Preoperative diagnostic workup included clinical assessment, laboratory investigations, tumor markers as CEA and CA19-9, radiological investigations (abdominal ultrasound, magnetic resonance cholangiopancreatography MRCP, and abdominal computerized tomography). Preoperative biliary drainage was performed by endoscopic retrograde cholangiopancreatography (ERCP) in selected patients, with serum levels of total bilirubin greater than $10 \mathrm{mg} / \mathrm{dl}$ associated with hepatic dysfunction or/and with renal impairment $(2,11)$.

\section{Surgical procedures}

Standard pancreaticoduodenectomy operation was performed in 210 (73.4\%) patients while 77(26.8\%) patients underwent PAPD. All surgeons participated in the study are expertise surgeon (at least doing more than 50 PD and assists in more than 100 PD). In PAPD, we adapt complete dissection of the pancreatic head through posterior retroperitoneal approach starting from the supradoudenal portion down to the level below the pancreatic head where superior mesenteric vein (SMV), superior mesenteric artery (SMA) and uncinate process are identified, dissected and the vessels are completely skeletonized from the right side (22). The details of the surgical procedure were described in our previous study (22) (fig. $1 a, b$ ).

Pancreatic reconstruction was done by pancreaticogastrostomy (PG). Biliary drainage was achieved by end to side hepaticojejunostomy (retrocolic). Gastric drainage was achieved by gastrojejunostomy (GJ) (antecolic or retrocolic) (manual or using stapler). 

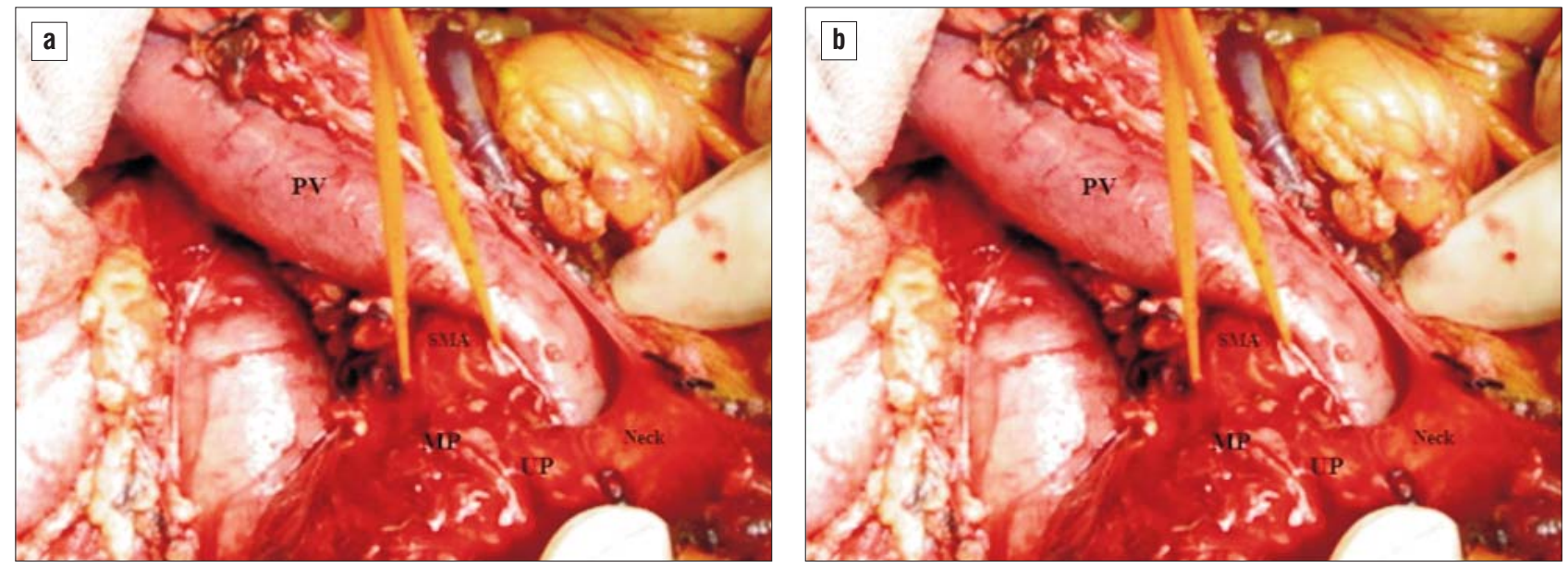

Figure 1 - (a) Posterior approach pancreaticoduodenectomy: after complete dissection of the portal vein (PV) and kocherization of the duodenum, starting dissection of the superior mesenteric artery (SMA) (yellow vascular sling) and mesopancreas. (PV): (UP): Uncinate Process, (MP): Mesopancreas. (b) Pancreaticoduodenectomy Posterior Approach: after complete mesopancreatectomy showing accessory right hepatic artery (ARHA) arising from the superior mesenteric artery (SMA). Portal Vein (PV), common hepatic artery (CHA), superior mesenteric vein (SMV), inferior vena cava (IVC).

\section{Postoperative management}

All patients were managed in the intensive care unit for at least one day before transfer to the ward. All patients received prophylactic antibiotics intraoperatively and for 4 days postoperatively. Prophylactic octreotide was given subcutaneously and continued postoperatively for 4 days, in patients considered high risk for pancreatic fistula.

All postoperative pathologic specimens were reviewed to show tumor size, tumor differentiation, lymph node status, surgical safety margins, perineural and perivascular invasion. Lymph nodes were considered to be histologically infiltrated if any lymph node in the resection specimen contained tumor. Lymph node ratio (LNR) was determined by dividing the total lymph node harboring a tumour metastasis by the total number of nodes resected. According to LNR, patients were then divided into 4 groups based on their $\operatorname{LNR}(0,0-0.2,0.2-0.4$, $>0.4)$ (23). The safety margin is marked by the surgeon (Lower end CBD, Pancreatic neck, Meso-pancrease, uncinate process). Surgical safety margins were considered infiltrated if the adenocarcinoma was present at any of the cut margins (24).

Postoperative pancreatic fistula (POPF) was defined as described by International Study Group of Pancreatic Fistula (ISGPF) as any measurable volume of fluid on or after postoperative day (POD) 3 with amylase content greater than 3 times the serum amylase activity, and classified into grades A, B, C. Delayed gastric emptying was defined as output from a Ryle tube of greater than
$500 \mathrm{ml}$ per day that persisted beyond POD10, the failure to maintain oral intake by POD 14, or reinsertion of a Ryle tube. Biliary leak was defined as the presence of bile in the drainage fluid that persists to POD 4 (25).

We routinely give our patient postoperative chemotherapy in the last 3 years. $18 / 77$ (23.4\%) patients underwent PAPD received postoperative chemotherapy and 55/210, (26.2\%) patients received postoperative chemotherapy. Till now, no difference in median survival in both groups as regards postoperative chemotherapy.

\section{Follow up}

Patients were followed up after 2 weeks, 3 months, 6 months, one year then annually until death or were lost to follow-up study. Each visit included a clinical examination, routine laboratory investigation (including complete blood picture, liver function, blood sugar and tumour markers CEA, CA19-9, abdominal ultrasound and abdominal computed tomography (CT) for patients searching for recurrence after resection.

The primary outcome was postoperative median survival. Survival was defined as the time period from the date of PD until death. The cause of death was unavailable for many patients, but in most patients where the cause of death was known, it was tumorrelated. Secondary outcomes were operative time, blood loss, blood transfusion, length of postoperative stay, LN status, surgical safety margin, postoperative complications, hospital mortality (which was defined as death occurring within one month after surgery), recurrence rate, and site of recurrence. 


\section{Statistical Analysis}

Statistical analysis of the data in this study was performed using SPSS software, version 17 (Chicago, IL). For continuous variables, descriptive statistics were calculated and were reported as mean with standard deviation. Categorical variables were described using frequency distributions. Independent sample t- test was used to detect differences in the means of continuous variables and Chi-square test was used in cases with low expected frequencies. Survival was calculated and plots constructed according to the Kaplan-Meier method and life table method. Whereas the log-rank test was used for comparison of survival in both groups. $P$ values • 0.05 were considered significant.

\section{RESULTS}

\section{Characteristics of patients}

A total of 520 consecutive patients underwent PD in our Gastroenterology Surgical Center, Mansoura University, Egypt, from January 2004 to December 2015. Of these $233(44.8 \%)$ were excluded from analysis. Therefore, the focus of the present analysis is 287 patients with histologically proven pancreatic adenocarcinoma who underwent curative pancreaticoduodenectomy. They were divided into two groups Group A 210 (73.2\%) patients who underwent standard PD and group B 77 (26.8\%) patients who underwent PAPD. Table 1 showed that both groups were matched as regards preoperative data including age, sex, body mass index (BMI), preoperative serum bilirubin, preoperative CA19-9, preoperative ERCP and intraoperative tumour size.

\section{Operative data}

The mean blood loss was significantly less in PAPD group than in standard group $(448.7 \pm 408.87 \mathrm{ml}$ vs. $623.52 \pm 502.1 \mathrm{ml}, \mathrm{P}=0.007)$. The number of patients needed blood transfusion were significantly more in standard PD group (table 2). The mean operative time was $4.4 \pm 0.61$ hours in PAPD group and $5.28 \pm 1.05$ hours in standard PD group but not statistically significant $(P=0.07)$. In Standard PD group vascular resection was done in two cases (one infiltrating part of portal vein and the other one infiltrating SMV) (the repair using prolene $6 / 0$ in one case without graft and the other one needed Goretex graft). In PAPD group, venous vascular involvement was recorded in two cases and repair was done using prolene $6 / 0$ without graft.

\section{Pathological data}

The number of patients with microscopically residual tumor was significantly higher after standard PD group than in PAPD group (22 (10.5\%) vs. $2(2.6 \%), \mathrm{P}=0.04)$. The number of lymph nodes resected in the specimen were significantly more in PAPD group than standard PD group (9.89 \pm 3.96 vs. $6.4 \pm 3.5$ respectively, $P=0.0001$ ) (table 2).

Table 1 - Demographic data

\begin{tabular}{|c|c|c|c|}
\hline & $\begin{array}{c}\text { Standard PD } \\
\text { (Group A) }\end{array}$ & $\begin{array}{c}\text { Posterior approach PD } \\
\text { (Group B) }\end{array}$ & \\
\hline $\begin{array}{l}\text { Age (years) } \\
<60 \text { years } \\
>60 \text { years }\end{array}$ & $\begin{array}{c}53.3 \pm 9.5(25-72) \\
151(71.9 \%) \\
59(28.1 \%)\end{array}$ & $\begin{array}{c}54.6 \pm 10.1(30-71) \\
55(71.4 \%) \\
22(28.6 \%)\end{array}$ & $\begin{array}{l}0.31 \\
0.93\end{array}$ \\
\hline $\begin{array}{l}\text { Sex } \\
\text { Male } \\
\text { Female }\end{array}$ & $\begin{array}{c}133(63.3 \%) \\
77(36.7 \%)\end{array}$ & $\begin{array}{l}50(64.9 \%) \\
27(35.1 \%)\end{array}$ & 0.8 \\
\hline $\begin{array}{l}\text { BMI } \\
<25 \\
>25\end{array}$ & $\begin{array}{c}150(71.4 \%) \\
60(28.6 \%)\end{array}$ & $\begin{array}{l}54(70.1 \%) \\
23(29.9 \%)\end{array}$ & 0.83 \\
\hline Preoperative ERCP & $105(50 \%)$ & $39(50.6 \%)$ & 0.92 \\
\hline $\begin{array}{l}\text { Preoperative bilirubin }(\mathrm{mg} \%) \\
\quad<5 \\
>5\end{array}$ & $\begin{array}{c}6.9 \pm 6.4(0.5-37) \\
188(56.2 \%) \\
92(43.8 \%)\end{array}$ & $\begin{array}{c}6.5 \pm 7.02(0.8-38) \\
\quad 44(57.1 \%) \\
33(42.9 \%)\end{array}$ & $\begin{array}{l}0.61 \\
0.88\end{array}$ \\
\hline $\begin{array}{l}\text { Preoperative CA19-9 (U/ml) } \\
\quad<37 \\
\quad>37\end{array}$ & $\begin{array}{c}96.2 \pm 201.14(0.2-1080) \\
121(57.6 \%) \\
89(42.4 \%)\end{array}$ & $\begin{array}{c}90.11 \pm 131.2(6-567) \\
43(55.8 \%) \\
34(44.2 \%)\end{array}$ & $\begin{array}{c}0.8 \\
0.78\end{array}$ \\
\hline
\end{tabular}


Table 2 - Intraoperative and pathological data

\begin{tabular}{|c|c|c|c|}
\hline Variables & $\begin{array}{l}\text { Standard PD } \\
\text { (Group A) }\end{array}$ & $\begin{array}{l}\text { Posterior approach PD } \\
\text { (Group B) }\end{array}$ & \\
\hline $\begin{array}{l}\text { Size of the mass } \\
\quad<2 \mathrm{~cm} \\
>2 \mathrm{~cm}\end{array}$ & $\begin{array}{c}3.2 \pm 0.69(1.5-5) \\
74(35.2 \%) \\
136(64.8 \%)\end{array}$ & $\begin{array}{c}3.32 \pm 0.81(2-5) \\
27(35.1 \%) \\
50(64.9 \%)\end{array}$ & $\begin{array}{l}0.44 \\
0.97\end{array}$ \\
\hline Operative time & $5.28 \pm 1.05(3.5-8)$ & $4.4 \pm 0.61(3.5-6)$ & 0.07 \\
\hline Blood loss (ml) & $623.52 \pm 502.1(100-3000)$ & $448.7 \pm 408.87(100-3000)$ & 0.007 \\
\hline $\begin{array}{l}\text { Blood transfusion } \\
\text { No of patients } \\
\text { Mean unite }\end{array}$ & $\begin{array}{c}102(48.6 \%) \\
0.88 \pm 1.15(0-4)\end{array}$ & $\begin{array}{c}27(35.1 \%) \\
0.35 \pm 0.54(0-3)\end{array}$ & $\begin{array}{c}0.0001 \\
0.04\end{array}$ \\
\hline $\begin{array}{l}\text { Lymph node } \\
\text { No of dissected LN } \\
\text { No of Lymph node infiltration } \\
\text { LN Ratio } \\
0 \\
\quad<0.2 \\
0.2-0.4 \\
>0.4\end{array}$ & $\begin{array}{c}6.4 \pm 3.5(1-15) \\
1.01 \pm 1.43(0-7) \\
116(55.2 \%) \\
49(23.3 \%) \\
17(8.1 \%) \\
28(13.3 \%)\end{array}$ & $\begin{array}{c}9.89 \pm 3.96(1-22) \\
0.98 \pm 1.3(0-6) \\
39(50.6) \\
28(36.4 \%) \\
6(7.8 \%) \\
4(5.2 \%)\end{array}$ & $\begin{array}{c}0.0001 \\
0.92 \\
0.07\end{array}$ \\
\hline $\begin{array}{c}\text { Safety margin } \\
\text { R0 } \\
\text { R1 } \\
\text { R2 }\end{array}$ & $\begin{array}{c}184(87.6 \%) \\
22(10.5 \%) \\
4(1.9 \%) \\
\end{array}$ & $\begin{array}{c}75(97.4 \%) \\
2(2.6 \%) \\
0 \\
\end{array}$ & 0.04 \\
\hline
\end{tabular}

\section{Postoperative and follow up data}

The mean postoperative hospital stay was longer in the standard PD group (11.02 \pm 7.94 days) vs. $(9.62 \pm 2.31$ days) in PAPD group but no significant difference between both groups $(\mathrm{P}=0.13)$ (table 3$)$. Seventeen postoperative complications were recorded in 10 patients (12.98\%) with PAPD and 52 complications were found in 42 patients (20\%) with standard PD (table 3). The POPF rate was higher in standard group vs. PAPD group, but

Table 3 - Postoperative and follow up data

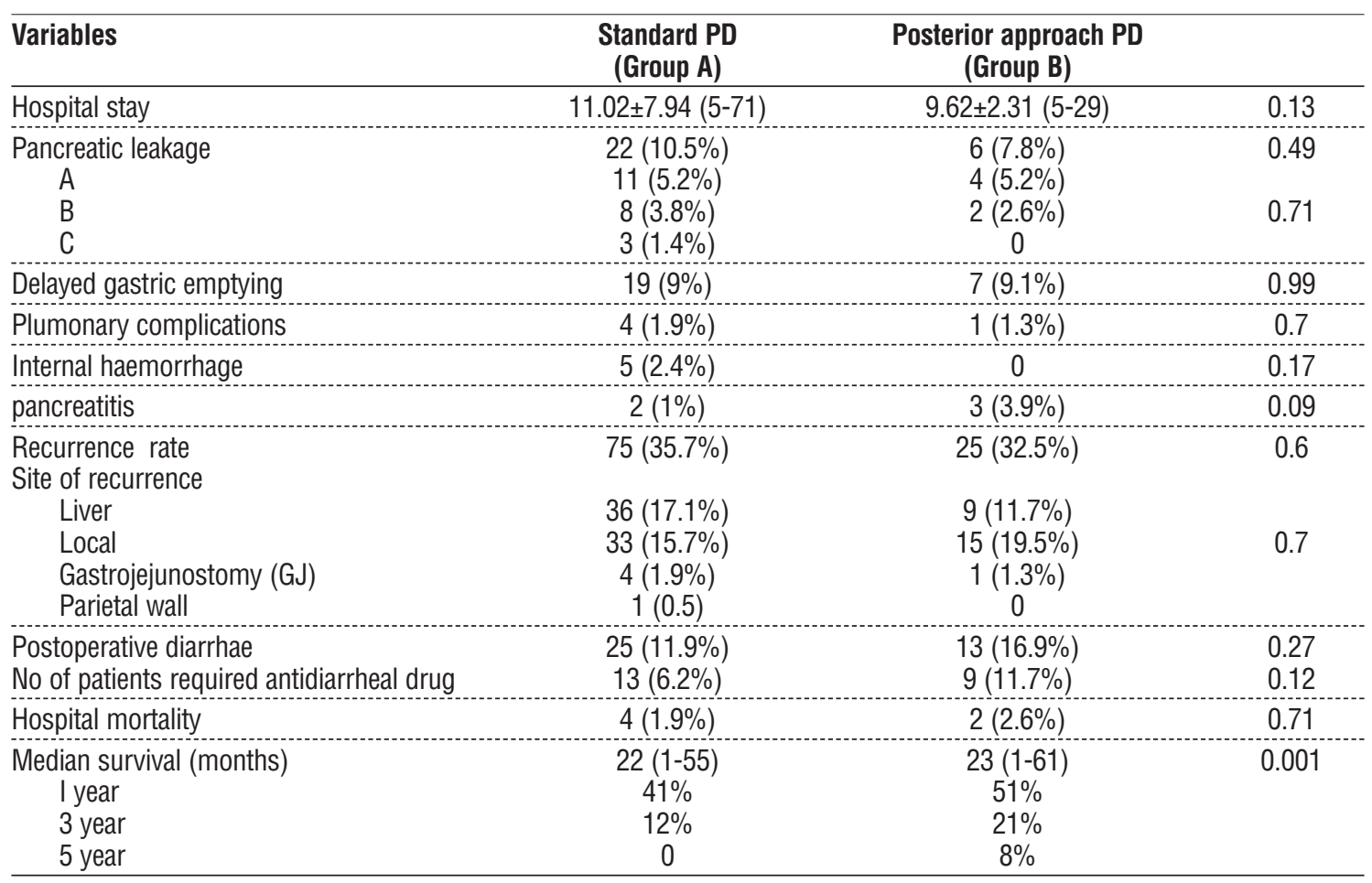


there was no statistically significant difference between both groups ( $P=0.49$ ). No significant difference as regards hospital mortality and recurrence rate between both groups (table 3).

The overall recurrence rate is slightly higher after standard PD than after PAPD (35.7\% vs $32.5 \%$ respectively $\mathrm{P}=0.6)$ and the postoperative liver metastasis developed more after standard PD (17.1\% vs $11.7 \%$, $\mathrm{P}=0.7$ ) (table 3).

At the time of analysis, 63 patients (30\%) in standard group and 26 patients (33.8\%) in PAPD group were still alive. The median survival was 22 months (range; 1-55 months) in standard groups and 23 months (range; 1-61) in PAPD group $(P=0.001)$. This corresponded to a 1 -, 3-and 5-year actuarial survival of $41 \%, 12 \%$, and $0 \%$ respectively in standard group and in PAPD group were $51 \%, 21 \%$,and $8 \%$ respectively (fig. 2 ).

\section{DISCUSSION}

Pancreatic ductal adenocarcinoma represented more than $90 \%$ of all pancreatic cancers. Over the last years, its incidence in Europe and the United States has increased significantly $(3,4,9)$. Pancreatic adenocarcinoma is one type of periampulary tumours demonstrating a worse prognosis than others. The incidence of resectability of pancreatic head adenocarcinoma is $10-15 \%$ (1-4). However, even after potentially curative PD, the 5- year survival rates after resection remain dismal about $5 \%$ to 20\% (3-7).

With advances in surgery, anesthesia and interventional radiology, operative mortality of PD has decreased from $30 \%$ down to $2-4 \%$ in high volume centers (4-7). However, postoperative morbidity is still high reaching up to $40 \%$ (4-6). Recently, much attention has been focused on refinement of operative technique especially surgical approach and management of pancreatic stump. One of the modifications in the surgical approach was Wahab posterior approach (22). Pessaux et al. describing the posterior approach in PD, $(17,18)$ Weitz et al $(26)$ describing their experience with superior mesenteric artery approach and lastly Kurosaki et al (27) described left posterior approach to superior mesenteric vascular pedicle.

Mesopancreas was first used standing for the firm well-vascularized fibrofatty tissue extending from the posterior surface of the pancreatic head to behind the superior mesenteric vessels (28.) It is the most common site for R1 resection and local recurrence (21). In this study 77 cases of PD was done by posterior dissection of the pancreatic head from the PV, SMV and SMA with complete excision of the mesopancreas compared with standard PD.

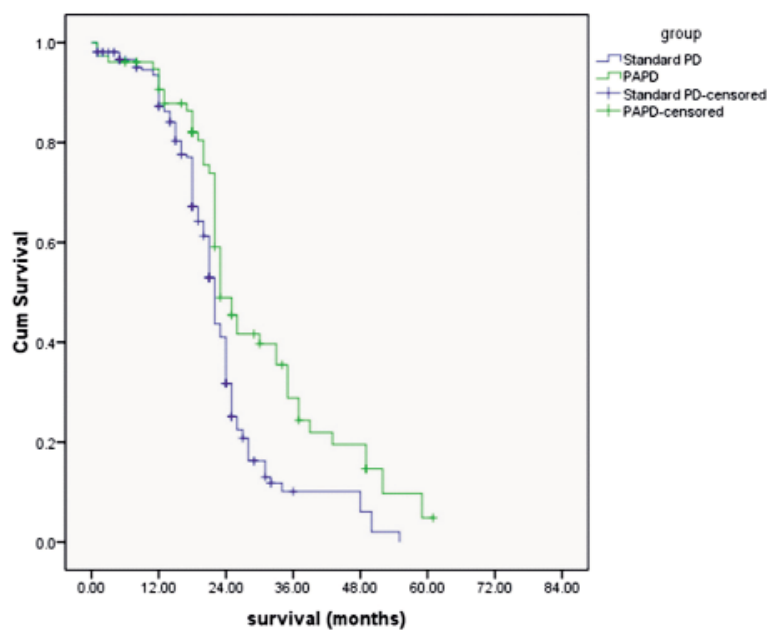

Figure 2 - Overall survival (Kaplan-Meier analysis) after resection of pancreatic cancer: influence of approach $(P=0.001)$

Increased operative blood loss and long operative time increase the risk of infection, pulmonary complications, hospital stay and cost (1-4). In our study, the mean blood loss was significantly lesser in PAPD group than in standard group and the number of patients needed blood transfusion were significantly more in standard PD. The mean operative time was shorter in PAPD group than in standard PD but statistically insignificant. In a case-match study, Dumitrascu et al (19) found that the mean operative time was shorter $(P=0.0002)$ and the mean blood loss was less $(P=0.0314)$ in the posterior approach than the standard approach. This can be attributed to rapid and easy dissection of PV and SMV from the pancreas and ligation and division of delicate veins draining the pancreatic head to the PV and SMV which are more liable to being stretched and torn during standard approach.

Posterior approach helps early detection of replaced right hepatic artery arising from $\operatorname{SMA}(17,18)$. This early detection is crucial in avoiding accidental injury of the replaced hepatic artery which is essential for good vascularity of the proximal CBD especially after ligation and division of the gastrodoudenal artery. The main concern if accidental injury occurs is biliary leakage due to ischemic bilio-enteric anastomosis (17-20). In this study, 12 cases (15.58\%) with aberrant right hepatic artery arising from the SMA was detected in PAPD group during posterior dissection of the pancreatic head and accidental injury didn't occur in any case. And we found 19 cases $(9.04 \%)$ with aberrant right hepatic artery arising from the SMA that was detected during standard PD dissection of the pancreatic head and accidental injury occurred in two cases.

The mean number of resected lymph is more in 
PAPD than in standard PD group. This relatively increased number of resected lymph nodes, compared to the number resected in the standard approach in our center experience, can be justified by easier dissection of peripancreatic, retroperitoneal and interaortocaval lymph nodes in the posterior approach. Impact of number of resected lymph nodes, positive to total lymph node ratio and value of extended lymphadenectomy in PD on short and long term outcomes is controversial and powerful randomized controlled trials are difficult to carry out to compare the results (29).

The PAPD enables complete dissection of right side of SMA and of the PV, as well as a complete excision of mesopancreas which leads to increased number of negative safety margin (RO), since it was found that the medial and posterior margin are most frequently infiltrated. The number of patients with microscopically residual tumor was significantly higher after standard PD group than in PAPD group $22(10.5 \%)$ vs. $2(2.6 \%)$, $\mathrm{P}=0.04)$.

Esposito et al reported that most of pancreatic cancer resections after standard PD are $\mathrm{R} 1$ resection up to $76 \%$ (30). Negative resection margin (R0) resections have an improved survival compared with microscopic positive safety margin (R1) resections, but this survival benefit is lost when the tumor is within $1 \mathrm{~mm}$ of the resection margin $(15,16)$. The majority of $\mathrm{R} 1$ margins are located at the retroperitoneal dissection surface (15). The PAPD allowed complete excision of mesopancreas which lead to an increased number of RO. Dumitrascu et al. reported that there was no difference between both groups regarding the number of RO resection and this reflected on the same long term survival on both groups. Also, He concluded that PAPD is better than standard PD in early assessment of SMA infiltration, thus avoiding $\mathrm{R} 1$ resection and $\mathrm{R} 2$ resection (19)

Direct dissection of the tumour from SMV and PV without using the no touch technique increased risk for intraportal tumour dissemination due to pressure on tumour during handling on standard PD and so increase postoperative liver metastasis $(17,18)$. In our study the recurrence rate is slightly higher after standard PD than after PAPD and the postoperative liver metastasis developed more after standard PD because of increased risk for intraportal tumour dissemination due to pressure on tumour during handling on standard PD.

In this study, The median survival was 22 months (range; 1-55 months) in standard groups and 23 months (range; $1-61)$ in PAPD group $(P=0.001)$. This corresponded to a 1-, 3-and 5-year actuarial survival of
$41 \%, 12 \%$, and $0 \%$ respectively in standard group and in PAPD were $51 \%, 21 \%$, and $8 \%$ respectively. This result may attribute to complete excision of mesopancreas by PAPD. Other contributing factors to this improved survival after PAPD are less operative time, less blood loss and better resection of lymph nodes. Dumitrascu et al. found that there was no difference between both groups regarding long term survival and this finding was explained due to no difference regarding the number of RO resection in both groups but his study was done in 20 cases in each group (small sample size) (19)

One of the limitations of this study is the retrospective nature of data collection but we use a computerized pancreatic surgery sheet since 2000 which had all preoperative, intraoperative and postoperative data for each patient (routine prospective practice). The other limitation of the study is that it was not randomized, however but it is well matched case control study as regards preoperative data including age, sex, body mass index (BMI), preoperative serum bilirubin, preoperative CA19-9, and preoperative ERCP. Nevertheless, further studies are necessary to prospectively validate these results.

\section{CONCLUSION}

Posterior approach PD achieves radical resection through complete removal of uncinate process with mesopancreas. It has the advantages of easier technique, early detection of variant vascular anatomy, more lymph node dissection, less blood transfusion, early detection of resectability, facilitation of portomesenteric venous resection, more radicality and less postoperative complication rate.

\section{Author contributions}

- Study conception and design: Mohamed Abd Elwahab; • Acquisition of data: Ayman El Nakeeb, Hosam Hamed, Ahmed Shehta, Mahmoud Ali, Rami Saied, Mohamed El Refea Ahmed El-Geidi; • Analysis and interpretation of data: Ayman El Nakeeb, Mahmoud Ali, Hosam Hamed, Ahmed Shehta; • Drafting of manuscript: Mohamed Abd Elwahab, Ayman El Nakeeb, Hosam Hamed, Ahmed Shehta, Talaat Abdallah; - Critical revision of manuscript: Mohamed Abd Elwahab, Ayman El Nakeeb, Talaat Abdallah.

\section{Conflict of interest}

No financial support. 


\section{REFERENCES}

1. Wagner M, Redaelli C, Lietz M, Seiler CA, Friess H, Büchler MW Curative resection is the single most important factor determining outcome in patients with pancreatic adenocarcinoma. Br J Surg. 2004;91(5):586-94.

2. El Nakeeb A, Atef E, El Hanafy E, Salem A, Askar W, Ezzat H, Shehta A, Abdel Wahab M. Outcomes of pancreaticoduodenectomy in elderly patients. Hepatobiliary Pancreat Dis Int. 2016;15(4):419-27.

3. Schmidt CM, Powell ES, Yiannoutsos CT, Howard TJ, Wiebke EA, Wiesenauer CA, et al. Pancreaticoduodenectomy: a 20- year experience in 516 patients. Arch Surg. 2004;139(7):718-25; discussion 725-7.

4. Yeo CJ, Sohn TA, Cameron JL, Hruban RH, Lillemoe KD, Pitt HA Periampullary adenocarcinoma: analysis of 5-year survivors. Ann Surg. 1998;227(6):821-31.

5. Geer RJ, Brennan MF. Prognostic indicators for survival after resection of pancreatic adenocarcinoma. Am J Surg. 1993;165(1): 68-72; discussion 72-3.

6. Trede M, Schwall G, Saeger HD. Survival after pancreaticoduodenectomy. 118 consecutive resections without a mortality. Ann Surg. 1990;211(4):447-58.

7. Jamieson NB, Denley SM, Logue J, MacKenzie DJ, Foulis AK, Dickson EJ. A prospective comparison of the prognostic value of tumor- and patient related factors in patients undergoingpotentially curative surgery for pancreatic ductal adenocarcinoma. Ann Surg Oncol. 2011;18(8):2318-28. doi: 10.1245/s10434-011-1560-3. Epub 2011 Jan 26.

8. Ueda M1, Endo I, Nakashima M, Minami Y, Takeda K, Matsuo K, et al. Prognostic factors after resection of pancreatic cancer. World $\mathrm{J}$ Surg. 2009;33(1):104-10. doi: 10.1007/s00268-008-9807-2.

9. Bassi C, Falconi M, Molinari E, Mantovani W, Butturini G, Gumbs AA, et al. Duct to mucosa versus end to side pancreaticojejunostomy reconstruction after pancreaticoduodenectomy: results of a prospective randomized trial. Surgery. 2003;134(5):766-71.

10. El Nakeeb A, Hamdy E, Sultan AM, Salah T, Askr W, Ezzat H, et al. Isolated Roux loop pancreaticojejunostomy versus pancreaticogastrostomy after pancreaticoduodenectomy: a prospective randomized study. HPB (Oxford). 2014;16(8):713-22. doi: 10.1111/ hpb.12210. Epub 2014 Jan 28.

11. El Nakeeb A, Salah T, Sultan A, El Hemaly M, Askr W, Ezzat H, et al. Pancreatic anastomotic leakage after pancreaticoduodenectomy. Risk factors, clinical predictors, and management (single center experience). World J Surg. 2013;37(6):1405-18. doi: 10.1007/ s00268-013-1998-5.

12. Dumitrascu T, David L, Popescu I. Posterior versus standard approach in pancreatoduodenectomy: a case-match study. Langenbecks Arch Surg. 2010;395(6):677-84. doi: 10.1007/ s00423-009-0499-3. Epub 2009 May 6.

13. Popescu I, David L, Dumitra AM, Dorobantu B. The posterior approach in pancreaticoduodenectomy: preliminary results. Hepatogastroenterology. 2007:54(75):921-6.

14. Sanjay P, Takaori K, Govil S, Shrikhande SV, Windsor JA. Artery-first approaches to pancreatoduodenectomy. Br J Surg. 2012;99(8): 1027-35. doi: 10.1002/bjs.8763. Epub 2012 May 9.

15. Rau BM, Moritz K, Schuschan S, Alsfasser G, Prall F, Klar E. R1 resection in pancreatic cancer has significant impact on long-term outcome in standardized pathology modified for routine use. Surgery.
2012;152(3 Suppl 1):S103-11. doi: 10.1016/j.surg.2012.05.015. Epub 2012 Jul 3.

16. Konstantinidis IT, Warshaw AL, Allen JN, Blaszkowsky LS, Castillo CF, Deshpande V, et al. Pancreatic ductal adenocarcinoma: is there a survival difference for $\mathrm{R} 1$ resections versus locally advanced unresectable tumors? What is a "true" R0 resection? Ann Surg. 2013; 257(4):731-6. doi: 10.1097/SLA.0b013e318263da2f.

17. Pessaux P, Varma D, Arnaud JP. Pancreaticoduodenectomy: superior mesenteric artery first approach. J Gastrointest Surg. 2006;10(4): 607-11.

18. Pessaux P, Regenet N, Arnaud JP. Resection of the retroportal pancreatic lamina during a cephalic pancreaticoduodenectomy: first dissection of the superior mesenteric artery. Ann Chir. 2003; 128(9):633-6. French

19. Gaedcke J, Gunawan B, Grade M, Szöke R, Liersch T, Becker H, et al. The mesopancreas is the primary site for $\mathrm{R} 1$ resection in pancreatic head cancer: relevance for clinical trials. Langenbecks Arch Surg. 2010;395(4):451-8. doi: 10.1007/s00423-009-0494-8. Epub 2009 May 6.

20. Popescu I, Dumitrascu T. Total meso-pancreas excision: key point of resection in pancreatic head adenocarcinoma. Hepatogastroenterology. 2011;:58(105):202-7.

21. Gaedcke J, Gunawan B, Grade M, Szöke R, Liersch T, Becker H, et al. The mesopancreas is the primary site for $\mathrm{R} 1$ resection in pancreatic head cancer: relevance for clinical trials. Langenbecks Arch Surg. 2010; 395(4):451-8. doi: 10.1007/s00423-009-0494-8. Epub 2009 May 6.

22. Abdel-Wahab M, Sultan A, elGwalby N, Fathy 0 , AboElenen A, Zied MA, et al. Modified pancreaticoduodenectomy: experience with 81 cases, Wahab modification. Hepatogastroenterology. 2001;48(42): 1572-6.

23. Pawlik TM, Gleisner AL, Cameron JL, Winter JM, Assumpcao L, Lillemoe KD, et al. Prognostic relevance of lymph node ratio following pancreaticoduodenectomy for pancreatic cancer. Surgery. 2007;141(5):610-8. Epub 2007 Mar 23.

24. Wittekind C, Compton CC, Greene FL, Sobin LH. TNM residual tumor classification revisited. Cancer. 2002;94(9):2511-6.

25. Bassi C, Dervenis C, Butturini G, Fingerhut A, Yeo C, Izbicki J, et al. Postoperative pancreatic fistula: an international study group (ISGPF) definition. Surgery. 2005;138(1):8-13.

26. Weitz J, Rahbari N, Koch M, Büchler MW. The "artery first" approach for resection of pancreatic head cancer. J Am Coll Surg. 2010; 210(2): e1-4. doi: 10.1016/j.jamcollsurg.2009.10.019. Epub 2009 Dec 3.

27. Kurosaki I, Minagawa M, Takano K, Takizawa K, Hatakeyama K. Left posterior approach to the superior mesenteric vascular pedicle in pancreaticoduodenectomy for cancer of the pancreatic head. JOP. 2011;12(3):220-9.

28. Gockel I, Domeyer M, Wolloscheck T, Konerding MA, Junginger T. Resection of the mesopancreas (RMP): a new surgical classification of a known anatomical space. World J Surg Oncol. 2007;5:44.

29. Nimura $Y$, Nagino M, Takao S, Takada T, Miyazaki K, Kawarada Y, et al. Standard versus extended lymphadenectomy in radical pancreatoduodenectomy for ductal adenocarcinoma of the head of the pancreas: long-term results of a Japanese multicenter randomized controlled trial. J Hepatobiliary Pancreat Sci. 2012;19(3):230-41. doi: 10.1007/s00534-011-0466-6.

30. Esposito I, Kleeff J, Bergmann F, Reiser C, Herpel E, Friess H, et al. Most pancreatic cancer resections are $\mathrm{R} 1$ resections. Ann Surg Oncol. 2008;15(6):1651-60. doi: 10.1245/s10434-008-9839-8. 